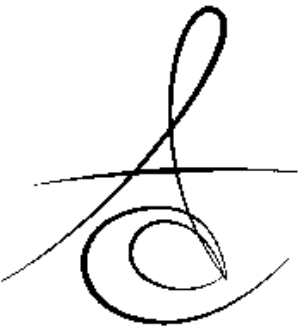

\section{DENTAL İMPLANT UYGULAMALARININ DEMOGRAFİK VE KLİNİK ÖZELLİKLERİNİN DEĞERLENDİRİLMESİ ${ }^{*}$}

\section{EVALUATION OF DEMOGRAPHIC AND CLINICAL FEATURES OF DENTAL IMPLANT APPLICATIONS ${ }^{*}$}

\author{
Yrd. Doç. Dr. Gelengül GÜRBÜZ URVASIZOĞLU*
}

Dr. Nesrin SARUHAN*
Makale Kodu/Article code: 2750

Makale Gönderilme tarihi: 30.03 .2016

Kabul Tarihi; 26.04.2016

\section{öz}

Amaç: Diş hekimliğinin güncel hedefi hastaların fonksiyonel ve estetik beklentilerini karşılayacak şekilde tedavi sunmaktır. Dental implant tedavisi; diş kayıplarının rehabilitasyonu için oldukça etkili bir metottur ve son yıllarda gittikçe artan sayıda uygulanmaktadır. Bu çalışmanın amacı; kliniğimizde dental implant cerrahisi uygulanan hastaların demografik ve klinik durumlarını ve yerleştirilen implantların özelliklerini retrospektif olarak incelemek ve tanımlayıcı istatistiksel yöntemler ile değerlendirmektir.

Gereç ve yöntem: Bu çalışmada 2014 ve 2015 yıllarında çalışma ekibimiz tarafından opere edilmiş hastalar yaş, cinsiyet, dişsizlik durumu, implant uygulanan bölgeler ve yerleştirilen implantların çeşitli özellikleri açısından incelenmiştir ve sonuçlar tanımlayıcı istatistiksel analiz metotları ile değerlendirilmiştir.

Bulgular: 20 erkek $(\% 29,9)$ ve 47 kadın $(\% 70,1)$ olmak üzere toplam 67 hasta ve toplam 233 dental implant değerlendirilmiştir. Hastaların yaş aralığı incelendiğinde; ortalama yaş 41,1'dir. En sık tedavi edilen yaş aralığı 4655 yaş arası olup toplam 20 hasta $(\% 29,8)$ olarak belirlenmiştir. 124 implantın maksillaya $(\% 53,2)$ ve 109 implantın ise mandibulaya $(\% 46,8)$ yerleştirildiği görülmüştür.

Sonuç: Bu çalışmada; dental implant uygulamalarının demografik ve klinik özelliklerinin değerlendirilmiş ve estetik alanda daha uzun ve daha dar çaplı, posterior alanda daha kısa ve daha geniş çaplı implantların kullanıldığı görülmüştür. En sık implant uygulaması gereksinimi duyulan maksiller ve mandibular birinci molar bölgelerine uygulanan implantların boyları ve çapları benzerlik göstermiştir.

Anahtar kelimeler: Retrospektif çalışmalar, dişsiz çene, diş implantları, implant destekli diş protezi

\section{ABSTRACT}

Aim: The contemporary goal of dentistry is to provide both infection control and treatment to satisfy the functional and aesthetic expectations. The dental implant treatment is a highly effective method for rehabilitation of tooth loss and is applied in increasing numbers in recent years. The aims of this study were to analyze retrospectively of the demographic data of patients undergoing dental implant surgery and properties of implants and to evaluate with the descriptive statistical methods.

Material and method:In this study, patients had been operated between 2014 and 2015 by our working team were evaluated. Patients studied in terms of age, gender, status of edentulism, implant zones and various features of these implants and datas evaluated with descriptive statistical analysis methods.

Results: 67 patients including 20 male (29,9\%) and 47 female $(70,1 \%)$ patients with 233 dental implants were evaluated. When the age range of patients estimated, mean age is 41.1 year and the most treated age range is $46-55$ years with 20 patient $(29,8 \%)$. It was observed that $124(53.2 \%)$ of implants were placed to maxilla and 109 (46.8\%) of implants were placed to mandible.

Conclusıon: In this study, demographic and clinical features of dental implant applications were evaluated and it's founded that longer and narrower implants were used in esthetic region and shorter and wider implants were used in posterior region. Implants were used for maxillary and mandibulary first molar tooth regions that are the most common implant application requirement regions, are similar in terms of length and diameter.

Key words: Retrospective studies, edentulous jaw, dental implants, implant-supported dental prosthesis

* Atatürk Üniversitesi Diş Hekimliği Fakültesi, Ağız Diş ve Çene Cerrahisi AD.

${ }^{\prime} \neq$ Bu çalışma 18-20 Mart 2016 tarihlerinde Erzurum/Türkiye'de düzenlenen "Türk Prostodonti ve Implantoloji Derneği 5. Uluslararası Palandöken Kış Sempozyumu"nda poster olarak sunulmuştur.

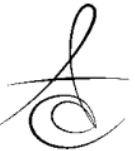




\section{GİRIŞ}

Diş hekimliğinin güncel hedefi, hastalar için enfeksiyon kontrolü sağlamanın yanı sıra fonksiyonel ve estetik beklentilerini karşılayacak şekilde tedavi sunmaktır. ${ }^{1}$ Dental implant tedavisi, diş kayıplarının rehabilitasyonu için oldukça etkili bir tedavi metodudur. $^{2,3}$ Ancak implantların yerleştirilmeleri ve uzun dönem başarılı kullanılabilmeleri için gerekli olan ön şartlardan biri stabilizasyon sağlamaya yetecek miktar ve kalitede kemik dokusu varlığıdır. ${ }^{2,4,5}$

Dental implantların satış hacminde, son 5 yılda ortalama \%12'lik bir artış olduğu bildirilmektedir. Bu mevcut veriler ile 2020 yılı için ortaya koydukları dental implant öngörüleri doğrultusunda; implant tedavisinin \%10'luk bir artışla tüm diş hekimliği tedavilerinin \%25-30'unu oluşturacağı öngörülmektedir. ${ }^{6} \mathrm{Bu}$ artışın sebepleri; yaşam süresinin uzaması, yaşa bağlı diş kayıpları, sabit protezlerde yaşanan problemler, dişsizliğin anatomik sonuçları, hareketli protezlerin zayıf tutuculuğu ve düşük hasta memnuniyeti, dişsizliğin olumsuz psikolojik sebepleri, implant üstü protezlerin uzun dönem olumlu sonuçları ve toplum bilincinin bu konuda artması olarak örneklenebilmektedir. ${ }^{1}$

$\mathrm{Bu}$ çalışmanın amacl; kliniğimizde dental implant cerrahisi uygulanan hastaların demografik bilgileri ve yerleştirilen implantların özelliklerini retrospektif olarak incelemek ve tanımlayıcı istatistiksel yöntemler ile değerlendirmektir.

\section{MATERYAL VE METOD}

Bu retrospektif çalışmada, 2014 ve 2015 yılları arasında Atatürk Üniversitesi Diş Hekimliği Fakültesi Ağız, Diş ve Çene Cerrahisi Anabilim Dalı'nda opere edilmiş 67 hastaya uygulanan 233 dental endoosseöz implant değerlendirilmiştir. Çalışmamıza dahil edilen implantlar; Astra Tech (Astra Tech AB, Mölndal, İsviçre), Bego Implant system (Bego, Bremen, Almanya), Implant Direct (Sybron International, California, $A B D$ ) ve Implance (AGS Medikal, Trabzon, Türkiye) marka dental implant sistemleridir. Hastalar; yaş, cinsiyet, dişsizlik durumu, implant uygulanan bölgeler, alt çeneye ve üst çeneye uygulanan toplam implant sayıları, implantların çapları ve uzunlukları, ek cerrahi işlemler açısından değerlendirilmiştir. Ayrıca implant yerleşimleri sonrasında diş-implant destekli protetik tedavi ihtiyacı oluşup oluşmadığı ve implant bölgesinin sabit bölümlü protez ile rehabilite edilecek durumda olup olmadığı kaydedilmiştir. Verilerin değerlendirilmesi amacıyla tanımlayıcı istatistiksel analizler yapılmıştır.

\section{BULGULAR}

Çalışmamızda, 20'si erkek $(\% 29,9)$ ve 47'si kadın $(\% 70,1)$ olmak üzere toplam 67 hasta ve toplam 233 dental implant değerlendirilmiştir. Hastaların yaş aralığı incelendiğinde; ortalama yaş 41,1 olarak görülmüş olup 18-25 yaş aralığında 9 hasta $(\% 13,4)$, 26-35 yaş aralığında 12 hasta $(\% 17,9), 36-45$ yaş aralığında 18 hasta (\%26,8), 46-55 yaş aralığında 20 hasta $(\% 29,8), 55-65$ yaş aralığında 7 hasta $(\% 10,4)$ ve 65 yaş üstü 1 hasta $(\% 1,4)$ olarak belirlenmiştir. (Grafik 1)

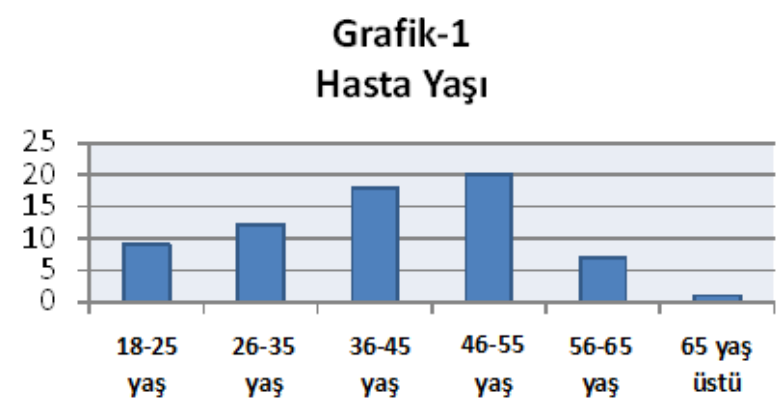

67 hastada implant yapılan 87 çenenin dişsizlik durumu incelenmiş ve en çok görülen dişsizlik durumunun dişsiz sonlanan kısmi dişsizlik (32 adet (\%37)) olduğu görülmüştür. Bunu takiben tek diş eksikliği (26 adet (\%30)), dişli sonlanan kısmi dişsizlik (21 adet (\%24)) ve en az sıklıkla tam dişsizlik (8 adet (\%9)) olarak görülmüştür.(Grafik 2)

Uygulanan implantların 124'ünün $(\% 53,2)$ üst çeneye ve 109 'unun $(\% 46,8)$ alt çeneye yerleştirildiği görülmüştür. En sık implant uygulanan bölge mandibular birinci büyük azı dişi bölgesidir $(\% 19,4)$ ve bu bölgeye uygulanan implantların uzunlukları 8-13 mm (ortalama 10,7 mm) ve çapları 3,3-4,8 mm (ortalama 4,0 mm) aralığındadır. Bunu 13,8'lik yüzde ile maksiller birinci molar dişin takip ettiği görülmüştür. Bu bölgeye uygulanan implantların uzunlukları ise $9-13 \mathrm{~mm}$ (ortalama 10,7 mm) ve çapları 3-5 mm (ortalama 3,9 mm). Alt anterior bölgenin $(\% 2,1)$ ise en az implant uygulanan alan olduğu tespit edilmiştir. (Grafik 3) 
Uygulanan implantların uzunlukları değerlendirildiğinde uzunluğun 8-15 mm (ortalama $11.26 \mathrm{~mm}$ ) olduğu görülmüştür (Grafik 4). Çalışma dâhilinde incelenen implantların çapları değerlendirildiğinde, implant çapının 3,0-5,2 mm (ortalama 3,85) olduğu belirlenmiştir (Grafik 5). Uygulanan implantların \%40'। (95 adet) estetik bölgededir (1. premolarlar arası) ve bu bölgede ortalama implant çapı 3,6 mm, ortalama implant uzunluğu ise $12,0 \mathrm{~mm}$ olarak belirlenmiştir. Uygulanan implantların \%60'ı ( 142 adet) ise posterior bölgeye (2. premolar ve arkası) uygulanmış olup, bu bölgede ortalama implant çapı 3,9 mm, ortalama implant uzunluğu $10,7 \mathrm{~mm}$ olarak görülmüştür. En uzun implant kullanılan bölge 12,4 mm ortalama uzunluk ile maksiller kanin bölgesi olarak ve bu bölgeye uygulanan implantların ortalama çapı 3,75 mm olarak belirlenmiştir.

\section{Grafik 2- Diş Eksikliği}

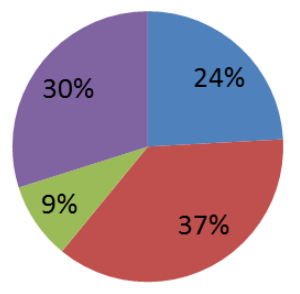

$$
\begin{aligned}
& \text { Dişli sonlanan } \\
& \text { kısmi dişsizlik } \\
& \text { Dişsiz sonlanan } \\
& \text { kısmi dişsizlik } \\
& \text { Tam dişsizlik } \\
& \text { Tek Diş Eksikliği }
\end{aligned}
$$

Grafik 3 - İmplant Bölgeleri

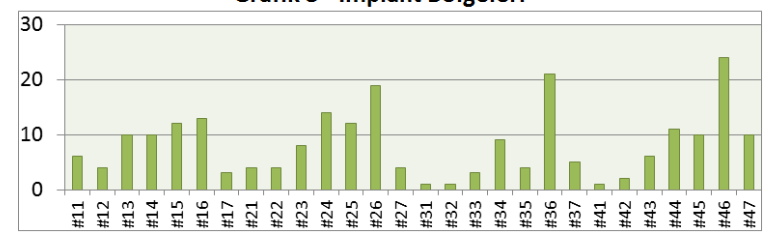

Grafik 4İmplant Uzunluğu (mm)

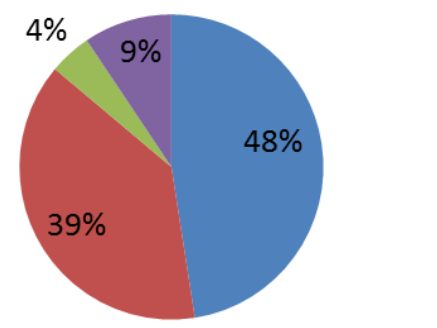

- 12-13,9

$\square 14+$

- 8-9,9

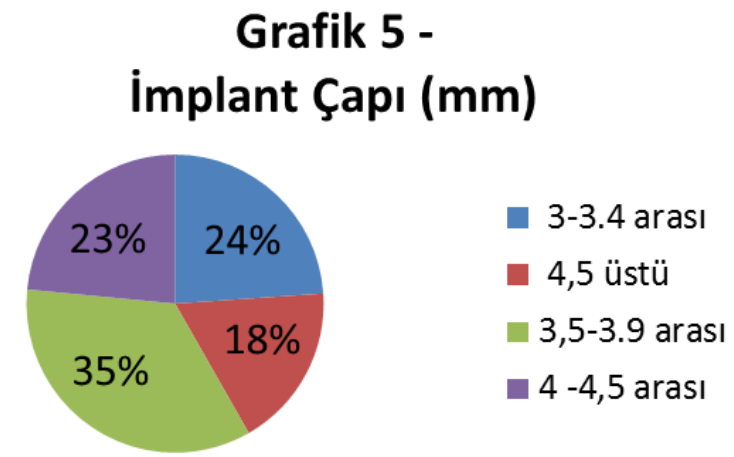

Uygulanan implantların 67'si için diş destekli sabit bölümlü protez endikasyonu bulunmadığı, \%33'ü için ise diş destekli sabit bölümlü protez yapılması mümkün olduğu halde implant destekli sabit protez uygulandığı görülmüştür. Diş-implant destekli tedavi planlaması görülmemiştir. Ek olarak implant bölgelerinin \%11.6'sında (7 adet implant bölgesi) ek cerrahi ihtiyacı olduğu, bunlar içerisinde ise en sık işlemin sinüs tabanının yükseltilmesi işlemi olduğu ve bunu sert doku grefti uygulamasının takip ettiği görülmüştür.

\section{TARTIŞMA}

Kemik içi implant destekli protezler, kayıp dişlerin yerine konması amacıyla kullanılacak başarılı, etkili ve sonuçları tahmin edilebilir bir tedavi şeklidir. ${ }^{7}$ Uzun süredir kullanılan dental implantların klinik uygulamalarına ait özelliklerinin retrospektif olarak değerlendirilmesi hekimlere yol göstermesi açısından oldukça değerlidir.8,9 Bu çalışmanın amacı, 2014 ve 2015 yıllarında Atatürk Üniversitesi Diş Hekimliği Fakültesi Ağız, Diş ve Çene Cerrahisi Anabilim Dalı́nda çalışma ekibimiz tarafından opere edilmiş implantlara ilişkin demografik ve klinik verilerin değerlendirilmesidir.

İmplant tedavi intiyacı, diş kaybı ile orantılı olarak yaş ile ilişkilidir. Vehemente ve ark. ${ }^{7}$ yaptıkları çaIışmada; ortalama yaşın 53,5 olduğunu ve yaş aralığının 16-92 aralığında değiştiğini bildirmişlerdir. Eltaş ve ark. ${ }^{10}$ yaptıkları çalışmalarında ise ortalama yaşın 45,2 olduğunu ve yaş aralığının 20-78 aralığında değiştiğini bildirmişlerdir. Çalışmamızda ise dahil edilen bireylerin yaş aralıkları incelendiğinde, en sık implant uygulanan yaş aralığının 46-55 yaş aralığı ve ortalama yaşın 41,1 olduğu görülmüştür.. Bu farklıı̆ı̆ sebebi, çalışma örnekleminin hacminin farklı olması olarak düşünülmüştür.

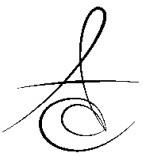


Hastaların dişsizlik durumu incelendiğinde; en sık görülen durumun dişsiz sonlanan kısmi dişsizlik (32 adet (\%37)) olması, çalışmanın yaş aralığının geniş ve ortalama yaşın benzer çalışmalara göre düşük olması ile ilişkilendirilebilir. ${ }^{11,12}$ Ayrıca tek diş eksikliği durumunun (26 adet (\%30) ve dişli sonlanan kısmi dişsizlik (21 adet (\%24)) klinik tablolarının da oldukça sık olduğu görülmüştür. Bu durum hastaların retansiyon ihtiyacından daha çok estetik ve komşu doğal dişlerin korunması hedefleri ile dental implant tedavisini talep ettiklerini gösteren bir bulgu olarak düşünülebilmektedir.

Uygulanan implantların \%40'ının estetik bölgeye, \%60'ının ise posterior bölgeye uygulandığı görülmüştür. Vehemente ve ark. ${ }^{7}$ yaptıkları çalışmada, çalışmamıza benzer olarak posterior alanda daha yüksek oranda implant uygulaması olduğunu göstermişlerdir. Çalışma sonuçlarımız değerlendirildiğinde; estetik alanda daha uzun ve daha dar çaplı implantların (ortalama implant çapı 3,6 mm, ortalama implant uzunluğu 12,0 $\mathrm{mm}$ ) kullanıldığı, ancak posterior alanda daha kısa ve daha geniş çaplı implantların (ortalama implant çapı $3,9 \mathrm{~mm}$, ortalama implant uzunluğu $10,7 \mathrm{~mm}$ ) tercih edildiği ortaya konulmuştur. Posterior maksilla için maksiller sinüs ve posterior mandibula için mandibular kanal dental implant cerrahisi açısından posterior bölgede anatomik sınırlayıcılardır. ${ }^{13,14} \mathrm{Bu}$ durum estetik bölgeye uygulanan implantların daha dar çaplı ve uzun olmasının sebebi olarak düşünülmektedir.

Kısmi dişsizlik görülen hastalarda fonksiyonun sağlanmasında implant uygulamalarının yeri ve önemi giderek artmaktadır. Hareketli bölümlü protezler ve total protezlere göre daha başarılı bir hasta konforu sunan implant destekli protezler hem hekimler hem de hastalar için oldukça tatmin edici klinik sonuçlar sağlamaktadır. ${ }^{15,16}$ Uygulanan implantların \%33'ü için diş destekli sabit bölümlü protez yapılması mümkün olduğu halde implant destekli sabit protez planlanmış olması klinik açıdan ele alındığında, hastaların fonksiyonel ve estetik beklentilerinin yanı sıra uzun süreli protez başarısı için de implant tedavisini tercih ettikleri yönünde yorumlanabilmektedir.

\section{SONUÇ}

Günümüzde implant tedavisi, diş eksikliklerinin tedavisinde her geçen gün kullanımı artan güvenilir bir tedavi alternatifidir. Çalışma sonuçlarımız değerlendi- rildiğinde, çalışmamızın geniş yaş aralığında olduğu ve farklı dişsizlik gruplarını kapsadığı görülmüştür. Estetik alanda ve posterior alanda kullanılan implantların çap ve uzunluklarının farklı olduğu görülmüştür. En sık implant uygulaması gereksinimi duyulan maksiller ve mandibular birinci molar bölgelerine uygulanan implantların boyları ve çapları benzerlik göstermiştir.

Bu veriler ışığında; dental implant tedavisine ait retrospektif çalışmalar bilgilendirici ve yönlendirici sonuçlar vermekte ve daha geniş, çok merkezli ve multidisipliner çalışmaların önemi görülmektedir.

\section{KAYNAKLAR}

1. Misch CE. Contemporary Implant Dentistry. Elsevier Health Sciences; 2007.

2. Chang $\mathrm{SH}$, Lin $\mathrm{CL}$, Hsue SS, Lin YS, Huang SR. Biomechanical analysis of the effects of implant diameter and bone quality in short implants placed in the atrophic posterior maxilla. Med Eng Phys 2012;34:153-60.

3. Putters TF, Schortinghuis J, Vissink A, Raghoebar GM. A prospective study on the morbidity resulting from calvarial bone harvesting for intraoral reconstruction. Int $\mathrm{J}$ Oral Maxillofac Surg 2015;44:513-7.

4. Marx RE. Alveolar Bone Augmentation via In Situ Tissue Engineering. Horiz Alveolar Ridge Augment Implant Dent A Surg Man. 2015:297.

5. Esposito M, Barausse C, Pistilli R, Sammartino G, Grandi G, Felice P. Short implants versus bone augmentation for placing longer implants in atrophic maxillae: One-year post-loading results of a pilot randomised controlled trial. Eur J Oral Implantol 2015;8.

6. Achermann G. How will dentistry look in 2020 ? In: Straumann Group. ; 2012.

7. Vehemente $V$ a, Chuang S-K, Daher S, Muftu A, Dodson TB. Risk factors affecting dental implant survival. J Oral Implantol 2002;28:74-81.

8. MacHtei EE, Mahler D, Oettinger-Barak $O$, Zuabi $O$, Horwitz J. Dental implants placed in previously failed sites: Survival rate and factors affecting the outcome. Clin Oral Implants Res 2008;19:259-64.

9. Wittneben J, Buser D, Salvi GE, Bürgin W, Hicklin $S$, Brägger U. Complication and Failure Rates with Implant-Supported Fixed Dental Prostheses and Single Crowns: A 10-Year Retrospective Study. Clin 
Implant Dent Relat Res. 2014;16(3):356-364.

10. Eltaş A, Dündar S, Uzun İH, Arslan Malkoç M. Assesement of Dental Implant Success and Patient Profile: a. Atatürk Üniv Diş Hek Fak Derg 2013;1:1-8.

11. Hogenius $S$, Berggren $U$, Blomberg $S$, Jemt $T$, Ohman SC. Demographical, odontological, and psychological variables in individuals referred for osseointegrated dental implants. Community Dent Oral Epidemiol 1992;20:224-8.

12. Kim J-S, Sohn J-Y, Park J-C, et al. Cumulative survival rate of Astra Tech implants: a retrospective analysis. J Periodontal Implant Sci 2011;41:86-91.

13. Woo I, Le BT. Maxillary sinus floor elevation: review of anatomy and two techniques. Implant Dent 2004;13:28-32.

14. Klinge $B$, Petersson A, Maly P. Location of the mandibular canal: comparison of macroscopic findings, conventional radiography, and computed tomography. Int J Oral Maxillofac Implants. 1989;4

15 Fernandez-Estevan L, Selva-Otaolaurruchi $E_{\text {, }}$ Montero J, Sola-Ruiz F. Oral health-related quality of life of implant-supported overdentures versus conventional complete prostheses: Retrospective study of a cohort of edentulous patients. Med Oral Patol Oral Cir Bucal 2015;20:1-2.

16. Thomason JM, Lund JP, Chehade A, Feine JS. Patient satisfaction with mandibular implant overdentures and conventional dentures 6 months after delivery. Int J Prosthodont 2003;16:1.

\author{
Yazışma Adresi \\ Nesrin SARUHAN \\ Atatürk Üniversitesi \\ Diş Hekimliği Fakültesi, \\ Ağız Diş ve Çene Cerrahisi Anabilim Dalı, \\ Erzurum, TÜRKIYYE. \\ Tel. 04422311801 \\ e-mail: dt_nesrin@yahoo.com
}

